RESEARCH REPORT

\title{
Association between childhood and adulthood socioeconomic position and pregnancy induced hypertension: results from the Aberdeen children of the 1950s cohort study
}

\author{
Debbie A Lawlor, Susan M B Morton, Dorothea Nitsch, David A Leon
}

J Epidemiol Community Health 2005;59:49-55. doi: 10.1136/jech.2004.020560

See end of article for authors' affiliations

Correspondence to: Dr D A Lawlor, Department of Social Medicine University of Bristol, Canynge Hall, Whiteladies Road, Bristol BS8 2PR, UK; d.a.lawlor@bristol.ac.uk

Accepted for publication 4 May 2004

\begin{abstract}
Background: Pregnancy induced hypertension may indicate a tendency towards endothelial and metabolic abnormalities leading to future cardiovascular disease. Childhood socioeconomic adversity is associated with increased cardiovascular disease risk but the association with pregnancy induced hypertension is unknown.

Aim: To examine the association of childhood and adulthood socioeconomic position with pregnancy induced hypertension.

Design: Historical cohort study with record linkage to obstetric data.

Subjects: 3485 women who were born in Aberdeen between 1950 and 1956 and delivered 7080 viable singleton offspring in the period up until to 1999.

Main outcome measure: Pregnancy induced hypertension (pre-eclampsia and gestational hypertension) in these women's pregnancies.

Results: Neither childhood nor adulthood socioeconomic position were associated with either preeclampsia or gestational hypertension. The fully adjusted odds ratio ( $95 \%$ confidence interval) comparing those born in manual social classes to those born in non-manual social classes for pre-eclampsia was 1.10 (0.72 to 1.73 ) and for gestational hypertension was 1.02 (0.83 to 1.32). Similar results comparing women in manual with non-manual social classes classified at the time of each pregnancy were 1.0910 .73 to 1.67$)$ for pre-eclampsia and $0.99(0.81$ to 1.30$)$ for gestational hypertension.

Conclusion: Although imprecise these results suggest that neither childhood nor adulthood socioeconomic adversity is associated with pregnancy induced hypertension.
\end{abstract}

$\mathrm{P}$ regnancy induced hypertension is one of the commonest complications of pregnancy and is associated with preterm delivery, fetal growth retardation, abruptio placentae, and maternal morbidity and mortality. ${ }^{12}$ Pregnancy induced hypertension may be complicated by proteinuria and/or oedema (pre-eclampsia) or it can occur in isolation (gestational hypertension). Both conditions are associated with the development of insulin resistance, the insulin resistance syndrome, essential hypertension, and cardiovascular disease events in later life..$^{3-13}$ These findings suggest that they may both be early adult manifestations of a tendency to endothelial and metabolic abnormalities, which are disclosed by the physiological stress of pregnancy, which in turn lead to future cardiovascular disease.

Adverse childhood socioeconomic position is associated with increased insulin resistance and cardiovascular disease risk in later life independently of adult socioeconomic position. ${ }^{14-17}$ This association between childhood socioeconomic adversity and adult cardiovascular disease is likely to involve a number of different pathways. From a policy perspective it is important to know whether early life socioeconomic adversity results in irreversible endothelial and metabolic dysfunction or whether there is a cumulative effect over the life course that may be modified by interventions in later life, thus alleviating all or part of much of the adverse effect of early deprivation. Examining the association between childhood socioeconomic position and pregnancy induced hypertension is one way of extending this area of research. An association between childhood socioeconomic adversity and pregnancy induced hypertension would provide some evidence that early life socioeconomic adversity is associated with endothelial and metabolic dysfunction that is present in early adulthood.

A few studies have examined the association between adult socioeconomic position and pregnancy induced hypertension and have found contradictory results: some have found poor socioeconomic circumstances around the time of pregnancy to be positively associated with pregnancy induced hypertension, ${ }^{18-20}$ one study found an inverse association with higher rates among the better off, ${ }^{21}$ and other studies have found no association. ${ }^{22-26}$ These contradictory results are likely to reflect differences in the study populations and differences in the range of potential confounding factors that each study was able to take into account. However, the absence of any clear evidence of an association between adult socioeconomic position and pregnancy induced hypertension does not preclude an effect of childhood socioeconomic position if childhood is the critical period for the establishment of the pathological processes that then lead to later disease.

The aim of this study is to assess the association between childhood and adulthood socioeconomic position and pregnancy induced hypertension in a large historical cohort. To our knowledge no previous study has examined the association between childhood socioeconomic circumstances and pregnancy induced hypertension.

\section{METHODS}

Study participants

The Aberdeen children of the 1950s study is a cohort of 12150 children (6276 boys, 5874 girls) who were born in Aberdeen, Scotland between 1950 and 1956 and who took 
part in a child development survey in the 1960s. ${ }^{27-29}$ Comprehensive information was abstracted from the Aberdeen Maternity and Neonatal Databank (AMND) about the course of their mother's pregnancy and their characteristics at birth (1950-1956). ${ }^{28}$ In 1999 this cohort study was revitalised and between 2000 and 2002, surviving cohort members were mailed a health questionnaire. ${ }^{27}$

\section{Obstetric record linkage}

Information regarding pregnancies of the female cohort members (1969-1999) was obtained from two sources: maternity discharge data (SMR2 records) and the AMND. ${ }^{30}$ The information and statistics division of the NHS in Scotland (ISD) used probabilistic matching based on five variables (current surname, maiden name, first and second initial, full date of birth, and postcode of residence) to obtain obstetric details for cohort members in all SMR2 delivery files. ${ }^{31}$ Obstetric data were also obtained by independent linkage to the AMND. This database, which has collated data on all obstetric events in women attending Aberdeen maternity hospitals since 1946, includes a linkage of women born in Aberdeen to their own offspring delivered in Aberdeen. ${ }^{32}$ Linkage was restricted to singleton deliveries of viable infants, defined as a birth weight of at least 500 grams and a gestational age of at least 24 completed weeks. Figure 1 outlines how information from these two data sources was merged and the data cleaning procedures undertaken. ${ }^{30}$

\section{RELIABILITY OF RECORD LINKAGE DATA AND SENSITIVITY ANALYSES}

Full perinatal information (birth weight, gestational age, father's occupation) at their birth was available for 4997 $(88.7 \%)$ of the original female cohort participants and of these, $3485(69.7 \%)$ were linked to valid records of their offspring pregnancies and deliveries, yielding 7080 singleton viable offspring (see fig 1). The remaining 1512 (30.3\%) study members were not linked to delivery records. These women will include those who have had no children at the time of the record linkage (women were aged between 43 to 49 years at the time of the linkage), those who had deliveries outside of Scotland, and also those who had deliveries in Scotland but for whom the linkage process failed.

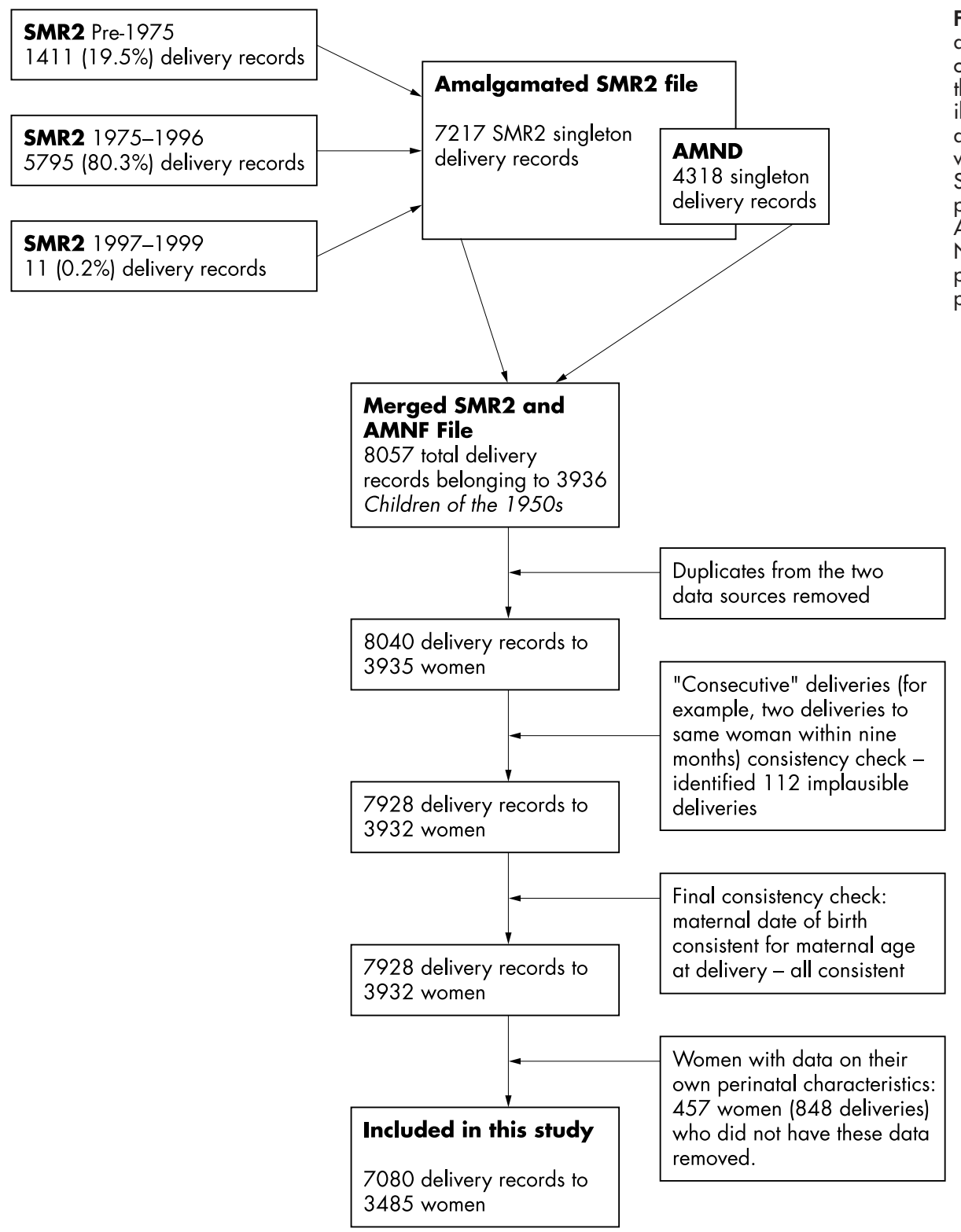

Figure 1 Flow diagram of the derivation and cleaning of information on pregnancies to female members of the children of the 1950s cohort. This illustrates how the participants and their deliveries for inclusion in this paper were obtained. Adapted from Morton. ${ }^{30}$ SMR, Scottish Morbidity Recordprovides hospital obstetric data; AMND, Aberdeen Maternity and Neonatal Database-obstetric and perinatal data collected on all pregnancies in Aberdeen since 1948. 
Table 1 Means (SD) and percentages (95\% confidence intervals) of pregnancy characteristics according to whether the offspring pregnancy $(n=7080)$ was complicated by a hypertensive disease

\begin{tabular}{|c|c|c|c|c|c|}
\hline & $\begin{array}{l}\text { Pregnancy not complicated by } \\
\text { any hypertensive disease* } \\
\text { ( } n=5295 \text { ) }\end{array}$ & $\begin{array}{l}\text { Pregnancy complicated } \\
\text { by pre-eclampsia } \\
(n=201)\end{array}$ & p Valuet & $\begin{array}{l}\text { Pregnancy complicated by } \\
\text { gestational hypertension } \\
\text { ( } n=1584 \text { ) }\end{array}$ & p Valueł \\
\hline $\begin{array}{l}\text { Maternal age at delivery } \\
\text { mean (SD) years }\end{array}$ & $25.5(5.3)$ & $24.8(4.9)$ & 0.04 & $25.1(4.7)$ & 0.001 \\
\hline \multicolumn{6}{|l|}{ Maternal age categories } \\
\hline$<20$ & $12.2(11.3$ to 13.1$)$ & 15.9 (11.2 to 21.7$)$ & & $10.2(8.7$ to 11.9$)$ & \\
\hline $21-35$ & $81.4(80.3$ to 82.4 ) & 81.1 (75.0 to 86.3 ) & & $86.2(84.4$ to 87.8$)$ & \\
\hline$\geqslant 36$ & $6.4(5.8$ to 7.1$)$ & $3.0(1.1$ to 6.4$)$ & 0.05 & $3.7(2.8$ to 4.7$)$ & $<0.001$ \\
\hline $\begin{array}{l}\text { Maternal smoking in pregnancy } \\
\%(95 \% \mathrm{Cl})\end{array}$ & 41.1 (39.4 to 42.9$)$ & 29.7 (23.3 to 36.9$)$ & 0.003 & 33.0 (30.0 to 36.2 ) & $<0.001$ \\
\hline Nulliparous \% $(95 \% \mathrm{Cl})$ & 38.9 (37.6 to 40.2 ) & $74.5(68.0$ to 80.1$)$ & $<0.001$ & $60.6(58.3$ to 62.8$)$ & $<0.001$ \\
\hline $\begin{array}{l}\text { Grandmother had pre-eclampsia in } \\
\text { mothers pregnancy } \\
\%(95 \% \text { Cl) }\end{array}$ & $3.6(3.1$ to 4.1$)$ & $8.1(4.8$ to 13.4$)$ & 0.004 & $4.8(3.8$ to 6.1$)$ & 0.05 \\
\hline $\begin{array}{l}\text { Grandmother had gestational } \\
\text { hypertension in mothers pregnancy } \\
\% \text { (95\% CI) }\end{array}$ & 13.6 (12.7 to 14.6$)$ & 21.3 (16.0 to 27.7$)$ & 0.003 & 19.0 (17.1 to 21.1$)$ & $<0.001$ \\
\hline $\begin{array}{l}\text { Birth weight of offspring } \\
\text { mean (SD) grams }\end{array}$ & $3302.8(548.6)$ & $3036.6(678.9)$ & $<0.001$ & $3330.8(551.5)$ & 0.10 \\
\hline $\begin{array}{l}\text { Gestational age of offspring } \\
\text { mean (SD) weeks }\end{array}$ & $39.5(1.9)$ & $38.5(2.5)$ & $<0.001$ & $39.5(2.0)$ & 0.67 \\
\hline $\begin{array}{l}\text { Standard deviation (Z) score of } \\
\text { offspring birth weight for } \\
\text { gestational age }\end{array}$ & $-0.06(1.00)$ & $-0.28(1.01)$ & 0.003 & $-0.04(0.99)$ & 0.29 \\
\hline
\end{tabular}

Female participants were asked about their obstetric histories in the questionnaire mailed to surviving cohort members. The response proportion to this questionnaire among surviving female cohort members was $68 \%$. Of the 3485 women who were linked to an offspring delivery 2399 (69\%) completed a questionnaire. There was exact agreement between their self report of number of children and the number of children they were allocated in the record linkage for 2001 (83\%) of these 2399 women, representing 4207 offspring. Of the 2399 questionnaire responders 344 reported a total of 454 offspring who were not identified through the record linkage procedure. Of these 454 offspring 138 (30\%) were born outside of Scotland, 258 (57\%) were born in Aberdeen, 46 (10\%) were born outside Aberdeen but in Scotland, and for $12(3 \%)$ no place of birth could be identified. Of the 258 births in Aberdeen 194 (75\%) were born before 1978. When the main analyses were repeated in the subgroup of 2001 women with 4207 pregnancies for whom there was exact agreement between questionnaire and record linkage there were no substantive differences to the results presented here.

There were 40 "false positive" offspring who were linked to 18 mothers who did not identify these offspring in their questionnaire response. The median (interquartile range) linkage score for these false positive links was 24 (22 to 32). In sensitivity analyses in which the analyses were repeated using higher thresholds of the linkage score for defining a link none of the results differed from those presented here. When the analyses were restricted to pregnancies identified in AMND only there were no substantive differences to the results presented here.

\section{Exposure and outcome assessment}

Pregnancy details, including occurrence of pregnancy induced hypertension, maternal age at delivery, maternal smoking during pregnancy, gestational age, birth weight, and sex of the infant were obtained from the linked SMR2 and AMND information (fig 1). The participant's own birth characteristics and details of whether her mother experienced pregnancy induced hypertension when the participant was in utero were recorded in the original study and were obtained from the AMND database in 1962.

For data from the SMR2 records pregnancy induced hypertension was coded using International Classification of Diseases (ICD) codes for obstetric discharges. Although these codes have standard definitions the data from SMR2 reflect standard clinical practice and the variation that occurs within that practice. Codes will tend to be applied based on the written diagnoses in the medical records and these may not always adhere to the standard definitions. For the AMND dataset specific criteria have been carefully applied since its inception and all obstetric records are reviewed, before being entered into the database, by obstetricians who apply agreed diagnostic criteria for the database. For these cases gestational hypertension was defined as diastolic pressure $\geqslant 90 \mathrm{~mm} \mathrm{Hg}$ on two occasions at least four hours apart or a single reading of $\geqslant 110 \mathrm{~mm} \mathrm{Hg}$ from 20 weeks' gestation in a previously normotensive woman. Pre-eclampsia was defined as gestational hypertension plus proteinuria of $\geqslant 0.3 \mathrm{~g} /$ 24 hours. Where data on pre-eclampsia were available from both SMR2 and AMND sources the AMND data were used. Furthermore, the analyses were repeated in the subgroup of women with linkages to the AMND database (that is, excluding those with SMR2 linkage) only and these results compared with the main results for the whole dataset.

Childhood social class was based on the occupations of the participant's fathers at the time of their birth (seven categories: I, professional; II, managerial; III-non-manual, skilled non-manual; III-manual, skilled manual; IV, semi-skilled; V, unskilled manual and unemployed, which were collapsed into two categories non-manual (I-IIINM) and manual (IIIM to $\mathrm{V}$ and unemployed)). Adult social class was based on the women's partner's occupations at the time of birth of their children and was categorised in a similar way to that for social class at birth.

\section{Statistical methods}

We used $\chi^{2}$ tests of independence and Student's $t$ test to compare prevalences and means of characteristics between 
Table 2 Odds ratios (95\% confidence intervals) of pregnancy induced hypertension during pregnancy comparing manual with non-manual social class at birth with adjustment for potential confounders

\begin{tabular}{|c|c|c|c|}
\hline $\begin{array}{l}\text { Covariate included in } \\
\text { adjusted model }\end{array}$ & $\begin{array}{l}\text { Number of pregnancies } \\
\text { in the subgroup with } \\
\text { complete data } \\
\text { on variable(s) included } \\
\text { in adjusted model }\end{array}$ & $\begin{array}{l}\text { Crude OR }(95 \% \mathrm{Cl}) \text { in the } \\
\text { subgroup with complete } \\
\text { data on variable }(\mathrm{s}) \\
\text { included in adjusted } \\
\text { model }\end{array}$ & $\begin{array}{l}\text { Adjusted OR } \\
(95 \% \mathrm{CI})\end{array}$ \\
\hline \multicolumn{4}{|l|}{ Outcome $=$ pre-eclampsia ${ }^{*}$} \\
\hline Adult social class & 5496 & $1.10(0.74$ to 1.64$)$ & $1.09(0.73$ to 1.63$)$ \\
\hline Maternal age & 5496 & 1.10 (0.74 to 1.64$)$ & $1.06(0.71$ to 1.57$)$ \\
\hline Parity & 5454 & $1.10(0.74$ to 1.64$)$ & $1.14(0.77$ to 1.69$)$ \\
\hline $\begin{array}{l}\text { History of pregnancy induced } \\
\text { hypertension in mother of } \\
\text { participant† }\end{array}$ & 5496 & $1.10(0.74$ to 1.64$)$ & $1.11(0.75$ to 1.65$)$ \\
\hline Smoking in pregnancy & 3089 & $1.08(0.71$ to 1.70$)$ & $1.14(0.75$ to 1.78$)$ \\
\hline $\begin{array}{l}\text { All potential confounding } \\
\text { factors } \ddagger\end{array}$ & 3089 & $1.08(0.71$ to 1.70$)$ & $1.10(0.72$ to 1.73$)$ \\
\hline \multicolumn{4}{|c|}{ Outcome = gestational hypertension ${ }^{*}$} \\
\hline Adult social class & 5496 & $1.06(0.90$ to 1.25$)$ & 1.05 (0.89 to 1.23$)$ \\
\hline Maternal age & 5496 & $1.06(0.90$ to 1.25$)$ & $1.02(0.87$ to 1.21$)$ \\
\hline Parity & 5454 & $1.06(0.90$ to 1.25$)$ & $1.08(0.91$ to 1.27$)$ \\
\hline $\begin{array}{l}\text { History of pregnancy induced } \\
\text { hypertension in mother of } \\
\text { participant† }\end{array}$ & 5496 & 1.06 (0.90 to 1.25$)$ & 1.07 (0.97 to 1.25$)$ \\
\hline Smoking in pregnancy & 3828 & $1.00(0.82$ to 1.31$)$ & 1.03 (0.83 to 1.33$)$ \\
\hline $\begin{array}{l}\text { All potential confounding } \\
\text { factorsł }\end{array}$ & 3828 & $1.00(0.82$ to 1.31$)$ & 1.02 (0.83 to 1.32$)$ \\
\hline \multicolumn{4}{|c|}{$\begin{array}{l}\text { Number varies and is given in first column for each set of models. *Both outcomes are compared with a referenc } \\
\text { group of no evidence of pregnancy induced hypertension. †During participant's intrauterine development. } ¥ A l l \\
\text { potential confounding factors: adult social class, maternal age, parity, smoking in pregnancy, history of pregnanc) } \\
\text { induced hypertension in participant of mother. Robust standard errors were used to take account of non- } \\
\text { independence of data. }\end{array}$} \\
\hline
\end{tabular}

women with pre-eclampsia or gestational hypertension with those with no evidence of pregnancy induced hypertension. Multiple logistic regression was used to assess the association between childhood and adulthood social class and both preeclampsia and gestational hypertension, taking into account potential confounding and mediating factors. In both sets of logistic regression models the reference group was women with no evidence of pregnancy induced hypertension. Robust standard errors, which take into account non-independence between repeated pregnancies within the same woman, were used to calculate p values and 95\% confidence intervals in all models. There were missing data for each potential confounder, this was particularly so for smoking during pregnancy, which was only consistently recorded in AMND records. The effect of adjustment for potential confounding factors has been assessed by comparing the crude association with the adjusted association for each individual covariate just on the subgroup of women with complete data on that covariate. Maternal age at the time of pregnancy (two yearly categories), parity, smoking during pregnancy (none, $\leqslant 10,11-20,>20$ per day), the participant's mother's history of pregnancy induced hypertension (none, gestational hypertension, and pre-eclampsia), and adult social class were entered as indicator variables. A similar series of regression models were used to assess the association between social class at the time of pregnancy and both manifestations of pregnancy induced hypertension. $F$ tests were used to assess statistical evidence for an interaction between childhood and adult social class - that is, to discover if the effect of childhood manual social class on pregnancy induced hypertension differed between women who were in manual social classes as adults and those who were in nonmanual social classes. Stata version 8.0 (Stata Corporation, TX, 2002) was used for all analyses.

\section{Research ethics}

The Scottish multicentre research ethics committee and local research ethics committees plus the Scottish Privacy Advisory
Committee approved the revitalisation of the Aberdeen children of the 1950s cohort. All record linkage to the SMR2 was undertaken by ISD, who provided us with an anonymised dataset for analysis.

\section{RESULTS}

The linkage procedure identified 7080 singleton live births to 3485 cohort women (fig 1). Among these 3485 women 192 $(5.5 \%)$ had at least one pregnancy complicated by preeclampsia and an additional $1223(35.1 \%)$ had gestational hypertension. Of the 7080 pregnancies 201 (2.8\%) were complicated by pre-eclampsia and an additional $1584(22.4 \%)$ were complicated by gestational hypertension. Table 1 shows means and prevalences of pregnancy characteristics by whether the pregnancy was complicated by pregnancy induced hypertension or not. Our results for these associations are in the same direction and of similar magnitudes to what one would expect based on consistent results from previous studies.

\section{Association of childhood socioeconomic position with pre-eclampsia and gestational hypertension}

The proportion of women from manual social classes at birth among those with no history of pregnancy induced hypertension did not differ from those who experienced pre-eclampsia in at least one pregnancy ( $82.1 \%$ compared with $80.8 \%$, $\mathrm{p}=0.63$ ) or from those who experienced gestational hypertension $(82.1 \%$ compared with $81.5 \%, p=0.75)$. Table 2 shows the association of childhood social class with preeclampsia and gestational hypertension in various subgroups of the study population defined according to the data available on potential confounders. Although smoking in pregnancy tends to mask the association, there was no robust evidence in any of the models for an association between childhood social class and either pre-eclampsia or gestational hypertension. The fully adjusted odds ratio (95\% confidence interval) comparing those born in manual social classes with 
Table 3 Odds ratios (95\% confidence intervals) of pre-eclampsia during pregnancy for different indicators of socioeconomic position in mid-life, with adjustment for potential confounders

\begin{tabular}{|c|c|c|c|}
\hline Indicator of adult SEP & $\begin{array}{l}\text { Number of pregnancies } \\
\text { with complete data on } \\
\text { SEP indicator and all } \\
\text { confounders }\end{array}$ & $\begin{array}{l}\text { Crude OR }(95 \% \mathrm{Cl}) \\
\text { in subgroup with } \\
\text { complete data }\end{array}$ & Adjusted* OR (95\% Cl) \\
\hline $\begin{array}{l}\text { Adult manual social class } \\
\text { based on husband's } \\
\text { occupation at time of } \\
\text { pregnancy }\end{array}$ & 3089 & 1.09 (0.73 to 1.67$)$ & 1.09 (0.73 to 1.67$)$ \\
\hline $\begin{array}{l}\text { Adult manual social class } \\
\text { based on participant's } \\
\text { occupation at follow up } \\
\text { questionnaire }\end{array}$ & 1829 & 0.95 (0.60 to 1.48$)$ & $0.96(0.61$ to 1.51$)$ \\
\hline $\begin{array}{l}\text { No car access as adult } \\
\text { (based on follow up } \\
\text { auestionnaire) }\end{array}$ & 1922 & 0.98 (0.66 to 1.49 ) & 0.99 (0.66 to 1.50$)$ \\
\hline $\begin{array}{l}\text { Low incomet (based on } \\
\text { follow up questionnaire) }\end{array}$ & 1881 & 1.06 (0.69 to 1.64$)$ & 1.05 (0.68 to 1.64 ) \\
\hline \multicolumn{4}{|c|}{$\begin{array}{l}\text { Number varies and is given in first column for each set of models. *Social class at birth, maternal age at } \\
\text { pregnancy, smoking in pregnancy, parity, history of pregnancy induced hypertension during participant's } \\
\text { intrauterine development. †Participant's own personal gross income less than } £ 20000 \text { per year or } £ 400 \text { per week } \\
\text { Robust standard errors were used to take account of non-independence of data. }\end{array}$} \\
\hline
\end{tabular}

those born in non-manual social classes for pre-eclampsia was 1.10 (0.72 to 1.73$)$ and for gestational hypertension was $1.02(0.83$ to 1.32$)$.

\section{Association of adulthood socioeconomic position with pre-eclampsia and gestational hypertension}

Adult social class at the time of each pregnancy was not associated with pre-eclampsia or any gestational hypertension. The fully adjusted odds ratio (95\% confidence interval) comparing manual with non-manual social classes at the time of pregnancy for pre-eclampsia was 1.09 (0.73 to 1.67) and for gestational hypertension was 0.99 (0.81 to 1.30). As adult socioeconomic position is associated with cardiovascular disease and risk factors this result was somewhat surprising. We therefore examined this further by looking at the association of our outcomes with a range of measures of socioeconomic position in middle age derived from responses to the postal questionnaire survey (table 3 ). Although results are imprecise, none of these indicators of socioeconomic position in middle age seem to be convincingly associated with pre-eclampsia. Gestational hypertension did not show any evidence of an association (not shown). There was no evidence of a statistical interaction between childhood and adult social class (based on partners occupation at time of pregnancy) in their associations with either pre-eclampsia $(p=0.32)$ or pregnancy induced hypertension $(p=0.65)$.

\section{Associations of socioeconomic position with pregnancy induced hypertension in the previous generation (mothers of study subjects)}

In the children of the 1950s cohort we were able to examine these same associations in the immediately preceding maternal generation. Among the mothers of the study subjects there was no association between either adult or childhood socioeconomic position and pregnancy induced hypertension. The age, parity, and adult social class adjusted odds ratio for the participant's mother having pre-eclampsia in the participant's intrauterine period was 1.16 (0.88 to 1.57$)$ and that of the participant's mother having gestational hypertension was 0.99 (0.87 to 1.13$)$ based on the social class of the mother's father. The equivalent odds ratios based on social class of the mother's husband at the time of the subject's birth were 1.10 (0.80 to 1.54 ) and 1.12 (0.93 to 1.35). Data were not available to adjust for smoking and other potential covariates in this generation, but these associations are con- sistent with those for the participants (the next generation) presented in tables 2 and 3. There was no association between one's mother having pregnancy induced hypertension and being linked to delivery of a viable singleton offspring (those included in the main analysis): odds ratio of being linked to an offspring delivery comparing those with maternal pre-eclampsia with those with no such history with adjustment for maternal age and parity was 1.03 (0.77 to $1.40)$ and the similarly adjusted odds ratio associated with maternal gestational hypertension was 1.09 (0.93 to 1.27).

\section{DISCUSSION}

Our results suggest that neither social class at birth nor in adulthood is associated with increased risk of pregnancy induced hypertension. While some of our results are imprecise, because of missing data, none of the point estimates from any of the models suggested an important effect.

\section{Study strengths and limitations}

To our knowledge this is the first study to examine the association of childhood socioeconomic position with pregnancy induced hypertension. Missing data, particularly on smoking during pregnancy was an important weakness with only $50 \%$ of all pregnancies having complete data on all potential explanatory variables. However, the crude associations of childhood social class with pre-eclampsia in different subgroups of women with complete data on different covariates were all consistent with each other, suggesting that selection bias because of missing data was negligible.

Another potential weakness is the quality and completeness of record linkage. Our reliability check suggested that the linkage was highly specific with very few women being linked to the offspring of other women. The sensitivity analyses with changing thresholds for linkage scores provides further evidence that the results are not affected by false positive linkages. However, the record linkage procedure clearly under-represented the total number of pregnancies to female cohort participants. The linkage was initially undertaken to examine transgenerational effects on birth weight and therefore only single viable births were included, which means that women who experienced an associated pregnancy loss or had multiple births, both of which are associated with pregnancy induced hypertension, were not included. In addition, our comparison with questionnaire responders found that births before 1978 that occurred in Aberdeen 
were often missed. These earlier pregnancies are more likely to be first pregnancies and are therefore more likely to have been affected by pre-eclampsia. Finally, those women who had births outside of Scotland could not be linked. Female cohort participants who left Scotland are more likely to be from higher social classes in childhood and to have lower parity. ${ }^{33}$ Missing pregnancies because of early loss, multiple birth, or failure of the linkage system would only importantly bias our results if the association among those who were not included in the analysis was considerably different to those who were. Although smoking data were not available for the participant's mothers for this preceding generation there is no exclusion of women because of linkage failure. It is nevertheless striking that results among this group of women were similar to those for their daughters who comprised the children of the 1950s cohort. This suggests that linkage problems have not importantly biased our results. Furthermore, pregnancy induced hypertension in the mother, which is strongly associated with the condition in the daughter, was not associated with the likelihood of a daughter being linked to a viable singleton offspring delivery and therefore included in the analysis, which again suggests that we do not have important missing cases. Finally, the associations of maternal age, parity, pregnancy induced hypertension in the previous generation, and smoking with pregnancy induced hypertension in our study were similar in magnitude to findings of other cohort studies ${ }^{23}{ }^{24}$ providing some further evidence that our results are not importantly affected by selection bias because of the exclusion of women who had children but who were not linked to our Scottish databases or because of missing data.

\section{Comparisons with other studies}

Results from other studies that have assessed the association between adult socioeconomic position and pregnancy induced hypertension have been contradictory. In a cohort of Mexican women the risk of pre-eclampsia was over three times greater among those delivering in a hospital for the uninsured compared with other women, ${ }^{19}$ and among South African teenagers there was a strong association between adult poverty and pre-eclampsia. ${ }^{20}$ However, associations among populations from developed countries have tended to agree with our results by largely finding no association. ${ }^{22-26}$ It is possible that the associations in developing populations represent poor antenatal care or that only extreme adult poverty influences the risk of pre-eclampsia.

Our findings are at odds with studies showing that both childhood and adult socioeconomic position are associated

\section{Key points}

- Pregnancy induced hypertension may point to a tendency to endothelial and metabolic abnormalities leading to future cardiovascular disease.

- Childhood socioeconomic adversity is associated with increased cardiovascular disease risk but the association with pregnancy induced hypertension is unknown.

- We have found no association between childhood socioeconomic position or socioeconomic position at the time of pregnancy and pregnancy induced hypertension.

- The association between childhood socioeconomic position and later life cardiovascular disease and risk factors does not seem to be manifest in early adulthood. with adult cardiovascular disease and risk factors measured in later adulthood. ${ }^{14-17}$ However, the evidence that socioeconomic position is associated with blood pressure measured in early life is less clear. ${ }^{34}$ Associations between adult socioeconomic position and blood pressure measured in later adulthood (usually measured in middle or old age) have found a consistent inverse association, but most studies of the association of socioeconomic position with blood pressure measured in childhood and early adulthood have found no association. $^{34}$ These findings are consistent with ours, as pregnancy induced hypertension by definition occurs in early adulthood during a woman's reproductive years. It is possible, therefore, that the association between childhood socioeconomic position and later life cardiovascular disease and risk factors is not manifest until middle age or later.

Our findings are potentially of relevance to policy. If we had found that childhood socioeconomic adversity was associated with pregnancy induced hypertension then this would imply endothelial dysfunction resulting from adverse early life circumstances was established in early adulthood. While treating hypertension is beneficial, ${ }^{35}$ treated and well controlled hypertensive adults still have a substantial excess mortality and reduced survival compared with normotensives $^{36}$ suggesting that once hypertension is established some permanent damage has occurred that despite good treatment and control does not return the person to the same risk as a normotensive person. Thus preventing hypertension in the first instance is clearly an important objective. The consistent finding of an association between childhood socioeconomic position and hypertension, other cardiovascular disease risk factors, and cardiovascular disease risk in older adult life, ${ }^{14-17}$ taken together with our finding of no association between childhood socioeconomic position and pregnancy induced hypertension suggests that adverse childhood socioeconomic position may influence later cardiovascular disease risk not through causing permanent damage in childhood or early adulthood, but by setting someone on a trajectory of risk exposures which together result in manifest disease in later life. There is, for example, evidence that adult behavioural risk factors to some extent mediate the association between childhood socioeconomic position and adult coronary heart disease. ${ }^{15}$ While our results should not be used to suggest measures aimed at reducing socioeconomic inequalities in childhood and adulthood are not important they do suggest that for contemporary young adults who were born in adverse circumstances their trajectory towards increased cardiovascular disease risk could be stopped.

\section{ACKNOWLEDGEMENTS}

We are very grateful to Raymond Illsley for providing us with the data from the Aberdeen child development survey and for his advice about the study. Graeme Ford played a crucial part in identifying individual cohort members and in helping us start the process of revitalisation. Sally Macintyre, Doris Campbell, George Davey Smith, Marion Hall, Bianca de Stavola, Susan Morton, David Batty, David Godden, Di Kuh, Debbie Lawlor, Glyn Lewis, and Viveca Östberg collaborated with David Leon to revitalise the cohort. Heather Clark managed the study at the Dugald Baird Centre, Aberdeen with the assistance of Margaret Beveridge. We would also like to thank staff at the ISD (Edinburgh), GRO (Scotland), and NHSCR (Southport) for their substantial contributions and John Lemon who undertook the linkage to the Aberdeen Maternity and Neonatal Databank. Finally, we thank the study participants who responded to a mailed questionnaire 40 years after the original survey was completed.

\section{CONTRIBUTORS}

D A Lawlor, D A Leon, and SMB Morton developed the idea for this study. D A Lawlor undertook the main analysis and D Nitsch undertook the reliability analyses. D A Lawlor wrote the first draft of the paper with all authors contributing to the final version. 


\section{Authors' affiliations}

D A Lawlor, Department of Social Medicine, University of Bristol, Bristol, UK

S M B Morton, School of Population Health, University of Auckland, Auckland, New Zealand

D Nitsch, D A Leon, Department of Epidemiology and Population Health London School of Hygiene and Tropical Medicine, London, UK

Funding: the Aberdeen children of the 1950s study is funded as a component project (G0828205) of a Medical Research Council Cooperative Group-Life-course and trans-generational influences on disease risk (G9819083). Debbie A Lawlor is funded by a Department of Health (UK) Career Scientist Award and Dorothea Nitsch is funded by the Medical Research Council. The views expressed in this publication are those of the authors and not necessarily those of any funding body.

Conflicts of interest: none declared.

\section{REFERENCES}

1 Chesley LC, Cosgrove RA, Annitto JE. A follow-up study of eclamptic women Am J Obstet Gynecol 1962:83:1360-72.

2 Chesley LC. History and epidemiology of preedlampsia-eclampsia. Clin Obstet Gynecol 1984;27:801-20.

3 Kaaja R, Laivuori $H$, Laakso $M$, et al. Evidence of a state of increased insulin resistance in preeclampsia. Metabolism 1999:48:892-6.

4 Kaaja R. Insulin resistance syndrome in preeclampsia. Seminars in Reproductive Endocrinology 1998;16:41-6.

5 Kaaja R, Tikkanen MJ, Viinikka L, et al. Serum lipoproteins, insulin, and urinary prostanoid metabolites in normal and hypertensive pregnant women. Obstet Gynecol 1995:85:353-6.

6 Berkowitz KM. Insulin resistance and preeclampsia. Clin Perinatol 1998;25:873-85.

7 Svensson A, Andersch B, Hansson L. Prediction of later hypertension following a hypertensive pregnancy. J Hypertens 1983;1:94-6.

8 Svensson A. Hypertension in pregnancy. Long-term effects on blood pressure in mothers and children. Acta Med Scand 1985;695:1-50.

9 Selvaggi L, Loverro G, Schena FP, et al. Long term follow-up of women with hypertension in pregnancy. Int I Gynaecol Obstet 1988;27:45-9.

10 Hannaford P, Ferry S, Hirsch S. Cardiovascular sequelae of toxaemia of pregnancy. Heart 1997;77:154-8.

11 Smith GC, Pell JP, Walsh D. Pregnancy complications and maternal risk of ischaemic heart disease: a retrospective cohort study of 129,290 births. Lancet 2001;357:2002-6.

12 Wilson BJ, Watson MS, Prescott GJ, et al. Hypertensive diseases of pregnancy and risk of hypertension and stroke in later life: results from cohort study. BMJ 2003;326:845

13 Sattar N, Ramsay J, Crawford L, et al. Classic and novel risk factor parameters in women with a history of preeclampsia. Hypertension 2003;42:39-42.

14 Lawlor DA, Ebrahim S, Davey Smith G. Socioeconomic position in childhood and adulthood and insulin resistance: cross sectional survey using data from the British women's heart and health study. BMJ 2002;325:805-7.

15 Lawlor DA, Davey Smith G, Ebrahim S. The association of childhood socioeconomic position with coronary heart disease risk in post-menopausal women: findings from the British women's heart and health study. Am J Public Health 2004;94:1386-92

16 Claussen B, Davey SG, Thelle D. Impact of childhood and adulthood socioeconomic position on cause specific mortality: the Oslo mortality study. J Epidemiol Community Health 2003;57:40-5.
17 Davey Smith G, Ben-Shlomo Y, Lynch J. Life course approaches to inequalities in coronary heart disease risk. In: Stansfeld S, Marmot M, eds. Stress and the heart. London: BMJ Books, 2002:20-49.

18 Zhang J, Klebanoff MA, Levine RJ, et al. The puzzling association between smoking and hypertension during pregnancy. Am J Obstet Gynecol 1999;181:1407-13.

19 Ceron-Mireles P, Harlow SD, Sanchez-Carrillo Cl, et al. Risk factors for preeclampsia/eclampsia among working women in Mexico City. Paediatr Perinat Epidemiol 2001;15:40-6.

20 Dlamini NJ. Factors associated with pre-eclampsia and quality care of affected teenagers during labour within health region $\mathrm{H}$. in Kwa-Zulu Natal. Curationis 1997;20:16-22.

21 Gudmundsson S, Bjorgvinsdottir L, Molin J, et al. Socioeconomic status and perinatal outcome according to residence area in the city of Malmo. Acta Obstet Gynecol Scand 1997;76:318-23.

22 Duffus GM, MacGillivray I. The incidence of pre-eclamptic toxaemia in smokers and non-smokers. Lancet 1968;i:994-5.

23 Sibai BM, Gordon T, Thom E, et al. Risk factors for preeclampsia in healthy nulliparous women: a prospective multicenter study. The National Institute of Child Health and Human Development Network of Maternal-Fetal Medicine Units. Am J Obstet Gynecol 1995; 172:642-8.

24 Eskenazi B, Fenster L, Sidney S. A multivariate analysis of risk factors for preeclampsia. JAMA 1991;266:237-41.

25 Kurki T, Hiilesmaa V, Raitasalo R, et al. Depression and anxiety in early pregnancy and risk for preeclampsia. Obstet Gynecol 2000;95:487-90.

26 Gonzalez AL, Ulloa GG, Alpuche G, et al. [Risk factors for preeclampsia. Multivariate analysis]. [Spanish]. Ginecol Obstet Mex 2000;68:357-62

27 Batty GD, Morton SMB, Campbell D, et al. The Aberdeen children of the 1950s cohort study: background, methods, and follow-up information on a new resource for the study of life-course and intergenerational effects on health. Paediat Perinat Epidemiol 2004;18:221-39.

28 Illsley R, Wilson F. Longitudinal studies in Aberdeen, Scotland. C. The Aberdeen child development survey. In: Mednick S, Baert A, Bachmann B, eds. Prospective longitudinal research. An empirical basis for the primary prevention of psychosocial disorders. Oxford: Oxford University Press, 1981:66-8.

29 Birch HG, Richardson SA, Baird D, et al. Mental subnormality in the community: a clinical and epidemiologic study. Baltimore: Williams and Wilkins, 1970

30 Morton SMB. Lifecourse determinants of offspring size at birth: an intergenerational study of Aberdeen women. [PhD thesis]. London: University of London, 2002

31 Kendrick S, Clarke J. The Scottish record linkage system. Health Bull 1993;51:72-9

32 Samphier ML, Thompson B. The Aberdeen maternity and neonatal data bank. In: Mednick SA, Baert AE, eds. Prospective longitudinal research. Oxford: Oxford University Press, 1981.

33 Jones ME, Swerdlow AJ. Bias caused by migration in case-control studies of prenatal risk factors for childhood and adult diseases. Am J Epidemiol $1996 ; 143: 823-31$

34 Colhoun HM, Hemingway H, Poulter NR. Socio-economic status and blood pressure: an overview analysis. J Hum Hypertens 1998;12:91-1 10.

35 Collins R, Peto R, MacMahon S, et al. Blood pressure, stroke, and coronary heart disease. Part 2, short-term reductions in blood pressure: overview of randomised drug trials in their epidemiological context. Lancet 1990;335:827-38.

36 Andersson OK, Almgren T, Persson B, et al. Survival in treated hypertension: follow up study after two decades. BMJ 1998;317:167-71. 